\title{
Participação masculina no uso de métodos contraceptivos
}

\author{
Male participation in contraceptive use
}

Graciana Alves Duarte 1

Augusta Thereza de Alvarenga 2

Maria José Duarte Osis 1

Aníbal Faúndes 1,3

Maria Helena de Sousa 1

\footnotetext{
1 Centro de Pesquisas Materno-Infantis de Campinas. C.P. 6181, Campinas, SP 13081-970, Brasil 2 Departamento de Saúde Materno-Infantil,

Faculdade de Saúde Pública, Universidade de São Paulo. Av. Dr. Arnaldo 715, São Paulo, SP 01246-904, Brasil

3 Departamento de Tocoginecologia, Faculdade de Ciências Médicas, Universidade Estadual de Campinas. C.P. 6181, Campinas, $S P$ 13081-970, Brasil
}

\begin{abstract}
This study aimed to evaluate male participation in the use of contraceptive methods and to identify relevant variables. A secondary data analysis was conducted, and the sample size was estimated at 175 men using contraceptives methods that require male participation. The study used the qui-square test to evaluate differences between groups, as well as multiple logistic regression analysis. Some 38\% of interviewees used some birth control method that required male participation. Higher level of schooling was associated with the use of some form of contraception requiring male participation, i.e., condom use or vasectomy. Considering the sample's characteristics, the study concluded that it is possible for important changes to take place in Brazilian society with regard to the male perspective on contraception. For these changes to be possible it is necessary to invest in education for both men and women, shown to be an important factor for a balance in gender relations.
\end{abstract}

Key words Contraception; Male Participation; Gender Relations

Resumo O objetivo deste trabalho foi avaliar o uso de métodos contraceptivos com participação masculina numa amostra de homens unidos e identificar variáveis que pudessem estar associadas a esta conduta. Trata-se de uma análise de dados secundários cujo tamanho amostral foi calculado em 174 homens que usavam métodos de participação masculina. Utilizou-se o teste qui-quadrado, para avaliar as associações das variáveis dependentes com as independentes, e a análise múltipla por regressão logística. Cerca de $38 \%$ dos entrevistados usavam algum contraceptivo de participação masculina. O maior grau de escolaridade relacionou-se ao uso de algum método de participação masculina, de preservativo (condom) e vasectomia. Levando-se em conta as características da amostra, considerou-se a possibilidade de concretizarem-se, na sociedade brasileira, mudanças importantes na perspectiva masculina quanto à contracepção. Para viabilizar tais mudanças, evidenciou-se a necessidade de investir na educação de homens e mulheres, uma vez que esta se apresentou como um divisor de águas no equilíbrio das relações de gênero.

Palavras-chave Anticoncepção; Participação Masculina; Relações entre Gêneros 


\section{Introdução}

Nas duas últimas décadas do século passado, em resposta à preocupação quanto ao papel e à perspectiva masculinos em relação à saúde reprodutiva, a participação dos homens nessa área passou a ser alvo de muitos estudos em todo o mundo. Nos anos 80 , três fatores desencadearam o interesse no papel masculino nessa área: um deles foi a epidemia da síndrome da imunodeficiência adquirida (AIDS) e seu avanço entre grupos heterossexuais, atingindo, portanto, também as mulheres; outro, as conquistas femininas em questões de saúde e de direitos reprodutivos, as quais colocaram em cena o homem; e o último, o avanço tecnológico na cirurgia da vasectomia, provocando um novo interesse da população masculina (Anonymous, 1992).

Em 1991, considerando a reivindicação pela participação dos homens na regulação da fecundidade, Azeredo \& Stolcke (1991) apontavam, com base em dados do Brasil e de outros países da América Latina sobre o uso de métodos contraceptivos, que a desigualdade em assumir a responsabilidade pela anticoncepção persistia naquele momento. Estudo posterior de Mundigo (1995) destacava que, no geral, o uso de métodos contraceptivos masculinos continuava baixo em nível mundial. Uma possível explicação para isso é que o maior número e variedade de opções anticoncepcionais para as mulheres podem contribuir para a baixa prevalência de uso de métodos pelos homens. A esse respeito, Ringheim (1996) aponta ser importante ressaltar que a descontinuação do uso de métodos contraceptivos de participação masculina é alta. Cerca de $60 \%$ dos usuários de tabela, preservativo (condom) e coito interrompido descontinuam o uso do método já no primeiro ano. A autora sustenta que a razão primária para isto é a alta taxa de falha de tais métodos.

Ao longo da década de 90, porém, foi-se cristalizando a convicção de que o homem tem papel importante com respeito à saúde reprodutiva do casal; de que o uso efetivo de métodos contraceptivos, e até mesmo a satisfação com o método escolhido, são freqüentemente influenciados pelo homem; de que ter o suporte do parceiro contribui para um melhor uso de métodos femininos e de que, para muitos casais, um método masculino pode ser uma excelente escolha (Anonymous, 1998).

Hulton \& Falkingham (1996), analisando dados de dez países, encontraram que a prevalência de uso de anticoncepcionais, relatada por homens e mulheres, foi semelhante. Isto pode sugerir, segundo os autores, que os homens estão cientes do comportamento contraceptivo de suas parceiras, o que poderia indicar também alguma forma de concordância (discutida ou não) do casal acerca do tema. Os autores também apontam que, apesar da baixa prevalência de uso de métodos contraceptivos pelos homens, o seu conhecimento de diferentes métodos era maior do que se esperava, visto que, historicamente, os homens têm sido negligenciados pelos programas de planejamento familiar.

Os dados da Pesquisa Nacional sobre Demografia e Saúde (PNDS) de 1996 indicavam uma alta prevalência de uso de métodos contraceptivos no Brasil, atingindo $77 \%$ das mulheres que viviam em união conjugal, com a ressalva de que a esterilização feminina e a pílula respondiam pela grande maioria dos contraceptivos em uso, com $40 \%$ e $21 \%$, respectivamente (BEMFAM/Macro International, 1997). Verificou-se que os homens em união, que referiram alguma prática contraceptiva, seja pelo uso de preservativo, pela vasectomia, seja pelo uso conjunto com sua parceira do coito interrompido e da tabela, respondiam por $19 \%$ dos métodos em uso (Badiani \& Camarano, 1998).

Por outro lado, comparando esses dados com os da Pesquisa Nacional sobre Saúde Materno-Infantil e Planejamento Familiar (PNSMIPF) de 1986 (BEMFAM/IRD, 1987), observa-se que o uso de preservativo e vasectomia, referido pelas mulheres unidas, passou de $1,7 \%$ a $4,4 \%$ e de $0,8 \%$ a $2,6 \%$, respectivamente, o que representa um aumento de duas e meia a três vezes nesse período de dez anos. Outro aspecto que chama atenção na PNDS de 1996, em que pela primeira vez entrevistaram-se homens, é que, entre os unidos, $5,2 \%$ citaram o preservativo como método contraceptivo em uso e $2,4 \%$ declararam ter feito vasectomia.

Há evidências, portanto, de que no Brasil estaria ocorrendo uma mudança de conduta dos homens quanto a sua responsabilidade reprodutiva. Não se sabe quanto dessa mudança resulta da maior consciência sobre a necessidade de proteger-se contra infecções de transmissão sexual e quanto é devido a uma real mudança nas relações de gênero. O presente trabalho foi desenvolvido com o objetivo de avaliar o uso de métodos contraceptivos com participação masculina numa amostra de homens unidos e identificar variáveis que pudessem estar associadas a esta conduta, incluindo alguns indicadores de gênero.

\section{Metodologia}

Trata-se de uma análise de dados de um estudo mais amplo intitulado Perspectiva Masculina 
Quanto a Métodos Contraceptivos, desenvolvido pelo Centro de Pesquisas Materno-Infantis de Campinas (Cemicamp), em uma universidade paulista. Os sujeitos sociais entrevistados na pesquisa original foram selecionados por amostragem sistemática, com base na listagem ordenada por categorias (docentes, alunos, funcionários e trabalhadores que atuavam especificamente no setor de obras da universidade), com o intuito de se ter amostragem estratificada com partilha proporcional ao tamanho de cada categoria; a cada sete homens $(K=7)$, selecionou-se um, e, para o início da seleção, sorteou-se um entre os sete primeiros nomes de cada lista. Quando, por algum motivo, não foi possível entrevistar, após três tentativas, o sujeito selecionado, o mesmo era substituído pelo seguinte da lista.

Foram entrevistados 129 docentes, 467 alunos, 263 funcionários e 51 trabalhadores do setor de obras, totalizando 910 entrevistas. Os dados foram coletados por meio de entrevistas individuais, para as quais se utilizou um formulário estruturado e pré-testado. Esse formulário continha perguntas pré-codificadas e outras em que a resposta deveria ser anotada textualmente. Os entrevistados foram convidados a participar voluntariamente, após serem informados de que se tratava de um estudo sobre métodos contraceptivos e planejamento familiar e que sua participação consistiria em responder a um formulário. Também lhes foi assegurado que a sua identidade seria sempre mantida em sigilo. Uma providência nesse sentido foi que os nomes não apareceram nos formulários, e as listagens fornecidas pela universidade, contendo os nomes, foram destruídas tão logo acabou o trabalho de campo.

Como os sujeitos eram homens, foram contratados doze entrevistadores do mesmo sexo, pensando-se em facilitar a comunicação e diminuir possíveis constrangimentos. Os entrevistadores passaram por treinamento, durante o qual foram instruídos sobre a forma de desenvolver a entrevista e de preencher o formulário, como localizar-se dentro da Universidade e como identificar os homens a serem entrevistados. Além dos entrevistadores, contratou-se um supervisor, que teve um dia a mais de treinamento, e deste constaram os seguintes assuntos: a forma de supervisionar o trabalho de campo, de maneira a dar suporte aos entrevistadores nas possíveis dificuldades; como revisar formulários preenchidos e quais as responsabilidades administrativas do supervisor junto à coordenação do estudo.

Para garantir a qualidade dos dados e dos resultados, cuidados foram tomados desde o planejamento da pesquisa: o pré-teste do formulário, a supervisão do desenvolvimento das entre- vistas, a revisão dos formulários e a dupla digitação dos dados, em ocasiões distintas, por pessoas diferentes, para detecção de possíveis erros de digitação.

Com base no banco de dados da pesquisa original, foi realizada uma análise da perspectiva masculina da anticoncepção e do aborto provocado, bem como o uso de métodos contraceptivos, entre os 361 homens que viviam em união conjugal legal ou consensual, uma vez que interessava analisar esta perspectiva no contexto das relações de gênero (para maiores detalhes acerca dos procedimentos metodológicos, veja-se Duarte, 2000). Como no presente trabalho será focalizado especificamente o uso de métodos com participação masculina, recalculou-se o tamanho amostral para saber se o número de sujeitos era suficiente para as análises apresentadas. Tomou-se como determinantes desse cálculo uma proporção de $13 \%$ de homens que usavam métodos contraceptivos de participação masculina (BEMFAM/DHS, 1997). Estimou-se uma diferença absoluta de cinco pontos percentuais entre a proporção amostral e populacional e com nível de confiança $(1-\alpha)$ de $95 \%$, o que resultou em 174 sujeitos sociais. Portanto, os 361 entrevistados que viviam em união conjugal legal ou consensual constituíram a amostra para esta análise.

Quanto à escolaridade, 53\% tinham nível universitário completo ou incompleto, e apenas $2 \%$ dos homens referiram não ter completado a primeira série do ensino fundamental. Em virtude da procedência dos sujeitos sociais, eram esperados níveis elevados de escolaridade superior, uma vez que já se sabia que, obviamente, as categorias docente e aluno apresentariam o nível universitário. A isto somou-se o fato de que $30 \%$ dos funcionários sorteados tinham curso superior. A maior parte das parceiras $(45 \%)$ tinha nível superior de escolaridade. A maioria dos sujeitos se autoclassificou como sendo da cor branca (78,8\%). As maiores rendas familiares foram referidas pelos docentes, $96,2 \%$ dos quais declararam renda de vinte ou mais salários mínimos; os trabalhadores do setor de obras foram os que apresentaram as menores rendas familiares, de maneira que cerca de $70 \%$ referiram renda inferior a cinco salários mínimos. Setenta por cento dos trabalhadores do setor de obras tinham três ou mais filhos por ocasião da entrevista, e nenhum deles referiu não ter filhos. Por outro lado, $41 \%$ dos alunos disseram que não tinham filhos.

Neste trabalho analisa-se a associação entre variáveis sócio-demográficas e reprodutivas e indicadores de gênero (independentes) e o uso de contracepção (dependente). Foram estuda- 
das as seguintes variáveis independentes, com suas respectivas categorias: grupo a que pertencia o sujeito social (docente/aluno; funcionário/trabalhador do setor de obras); idade (menos de 40 anos; 40 anos ou mais); número de filhos vivos (nenhum; um ou dois; três ou mais); renda familiar total (menos de 10 salários mínimos; de 10 a menos de 20 salários; 20 ou mais salários mínimos); escolaridade (até oitava série, ensino médio, superior); escolaridade da parceira (até oitava série, ensino médio, superior); participação no cuidado com os filhos (participavam ativamente: relataram que ajudavam a cuidar do(s) filho(s) e realizavam três ou mais tipos diferentes de tarefas; pouco participavam/não participavam: quando relataram que não dividiam as tarefas ou dividiam, mas realizavam no máximo dois tipos diferentes de tarefas); pessoa que escolheu o método contraceptivo em uso (casal, homem, mulher/médico); cor (branca, não branca).

Como variáveis dependentes, foram incluídas: método contraceptivo em uso; uso de método contraceptivo de participação masculina (sim, para qualquer dos seguintes métodos: preservativo, vasectomia, tabela e coito interrompido); uso de preservativo para prevenção da gravidez; uso de vasectomia. O teste qui-quadrado (Armitage \& Berry, 1987) foi utilizado para avaliar as associações entre as variáveis independentes e dependentes. Ao final, foi realizada análise múltipla por regressão logística (Hosmer \& Lemeshow, 1989). Consideraram-se, na análise múltipla, as seguintes variáveis independentes, com suas respectivas categorias: idade (em anos); escolaridade (até ensino médio: 0; superior: 1); cor (branca: 1; não branca: 0); grupo do sujeito (docente/aluno: 1; funcionário/trabalhador do setor de obras: 0); renda familiar (até 20 salários mínimos: 0; mais de 20 salários mínimos: 1); número de filhos vivos (até dois filhos: 0; mais de dois filhos: 1); escolaridade da parceira (até oitava série: 0 ; ensino médio ou mais: 1); indicador de "cuidado com os filhos" (até dois itens: 0; três ou mais itens de cuidado: 1); pessoa que escolheu o método contraceptivo (MAC) em uso (o próprio homem: 1; a mulher, o médico ou o casal: 0 ); esta variável, todavia, não foi incluída no primeiro modelo de regressão, pois se aplica apenas aos homens que declararam estarem usando eles próprios ou suas parceiras algum método contraceptivo por ocasião da entrevista. Foram desenvolvidos quatro modelos de regressão, um para cada uma das variáveis dependentes consideradas: modelo 1 - uso de algum método contraceptivo; modelo 2 - uso de preservativo; modelo 3 - uso de vasectomia; modelo 4 - uso de mé- todo contraceptivo de participação masculina. Os três últimos foram modelos específicos para homens que estavam usando algum MAC.

\section{Resultados}

\section{Prevalência de uso de métodos contraceptivos}

Todos os alunos, $80 \%$ dos funcionários, $75 \%$ dos docentes e $65 \%$ dos trabalhadores do setor de obras referiram estar usando algum método contraceptivo por ocasião da entrevista. As diferenças foram estatisticamente significativas. Os docentes citaram, principalmente, a laqueadura, a vasectomia e o preservativo. Entre os funcionários e trabalhadores do setor de obras, evidenciou-se o que se poderia chamar de "padrão" populacional brasileiro, aparecendo mais freqüentemente a laqueadura e a pílula. Entre os alunos, os métodos mais citados foram: pílula, preservativo e tabela. Com respeito ao uso da esterilização feminina, a diferença entre os grupos foi estatisticamente significativa, sendo maior a prevalência desse método entre os funcionários e trabalhadores do setor de obras (Tabela 1$)$.

\section{Variáveis relacionadas ao uso de métodos contraceptivos}

A prevalência de uso de MAC foi maior entre os homens que participavam ativamente nas tarefas relativas ao cuidado com os filhos, com renda familiar entre dez e menos que vinte salários mínimos, os de idade inferior a quarenta anos, escolaridade do homem ensino médio e da parceira superior, entre aqueles que referiram ter entre um e dois filhos e que se autoclassificaram como sendo de cor branca. Entretanto, as diferenças não foram estatisticamente significativas (Tabela 2). Quando realizada a análise por regressão logística, verificou-se que somente a menor idade estava associada ao uso de algum MAC (Tabela 3).

\section{Participação masculina no uso}

de métodos contraceptivos

Mais de um terço $(37,8 \%)$ dos entrevistados que referiram estar usando algum MAC usava métodos de participação masculina. A idade e o cuidado com os filhos foram as únicas variáveis que não estiveram estatisticamente associadas ao uso de tais métodos. Todos os homens que referiram ter sido eles próprios que escolheram o método em uso estavam utilizando métodos 
Métodos contraceptivos em uso por ocasião da entrevista, segundo grupo do entrevistado.

\begin{tabular}{|c|c|c|c|c|c|}
\hline Métodos & Docentes $(\%)^{\star}$ & Alunos (\%) & Funcionários (\%) & $\begin{array}{l}\text { Trabalhadores do } \\
\text { setor de obras (\%) }\end{array}$ & $p$ \\
\hline Nenhum & $27(25,5)$ & - & $35(19,0)$ & $15(34,9)$ & $<0,001$ \\
\hline Laqueadura & $20(18,9)$ & $5(18,5)$ & $56(30,4)$ & $17(39,5)$ & 0,029 \\
\hline Vasectomia & $17(16,0)$ & - & $16(8,7)$ & $1(2,3)$ & 0,012 \\
\hline Preservativo & $22(20,8)$ & $8(29,6)$ & $20(10,9)$ & $2(4,7)$ & 0,273 \\
\hline Pílula & $8(7,5)$ & $8(29,6)$ & $28(15,2)$ & $5(11,6)$ & 0,218 \\
\hline DIU & $7(6,6)$ & $2(7,4)$ & $18(9,8)$ & $1(2,3)$ & 0,313 \\
\hline Tabela & $10(9,4)$ & $7(25,9)$ & $5(2,7)$ & - & 0,018 \\
\hline Injetável & - & $2(7,4)$ & $2(1,1)$ & $1(2,3)$ & 0,028 \\
\hline Coito interrompido & $1(0,9)$ & $1(3,7)$ & $5(2,7)$ & $1(2,3)$ & 0,307 \\
\hline Diafragma & $1(0,9)$ & - & $1(0,5)$ & - & $\star \star$ \\
\hline Espuma/creme/geléia & - & - & $1(0,5)$ & - & $\star \star$ \\
\hline MAC combinados & $7(6,6)$ & $6(22,2)$ & $4(2,2)$ & - & $<0,001$ \\
\hline Total & 106 & 27 & 184 & 43 & \\
\hline
\end{tabular}

* Faltou informação de um entrevistado.

** Não foi possivel aplicar teste para avaliar.

de participação masculina. Entre os que relataram que a escolha foi do casal ou da parceira/ médico, as proporções foram duas e dez vezes menores, respectivamente. A prevalência de uso de métodos de participação masculina também foi maior entre docentes/alunos (duas vezes), entre os entrevistados com renda familiar maior ou igual a vinte salários mínimos, os que referiram que eles e as parceiras tinham o nível superior de escolaridade, entre os que se autoclassificaram como de cor branca e os que não tinham filhos (Tabela 2). Na regressão logística, esta última variável mostrou-se inversamente associada a estar usando um método de participação masculina, de maneira que o uso de MAC com participação masculina foi maior entre os entrevistados com até dois filhos do que entre os que tinham três ou mais filhos vivos (Tabela 3).

\section{Uso de preservativo e vasectomia}

Observou-se uma elevada proporção de uso de preservativo e vasectomia entre os entrevistados. Cerca de um em cada cinco estava usando o preservativo, e um em cada oito havia feito vasectomia por ocasião da entrevista (Tabela 4). Na análise por regressão logística, verificou-se que pertencer ao grupo docente/aluno, ter até dois filhos e ter sido o próprio homem que escolheu o método em uso estavam associados à utilização do preservativo (Tabela 5).

Mais da metade dos homens que referiram terem sido eles próprios que escolheram o mé- todo havia feito vasectomia, proporção que foi quatro vezes maior do que entre aqueles que decidiram com as suas parceiras, e mais de 25 vezes maior do que entre os que relataram que a decisão pelo MAC tinha sido da parceira/médico. As diferenças por renda também foram grandes. Pouco mais de $20 \%$ dos homens com renda familiar igual ou superior a vinte salários mínimos haviam feito vasectomia, porcentagem quase seis vezes maior que entre os homens com renda menor que dez salários mínimos, e três vezes maior que entre aqueles cuja renda era de dez a menos de vinte salários mínimos. As diferenças por escolaridade foram um pouco menores: a prevalência de vasectomia foi maior entre os homens com nível universitário. Por último, a prevalência de vasectomia foi maior entre os homens com um ou dois filhos (Tabela 4). $\mathrm{Na}$ análise por regressão logística, somente a pessoa que escolheu o método contraceptivo em uso (o próprio homem) e a renda familiar superior a vinte salários mínimos estiveram associados ao uso da vasectomia (Tabela 5).

\section{Discussão}

Na amostra estudada, verificou-se um compromisso masculino com a anticoncepção maior do que seria esperado, tendo em vista os dados populacionais existentes. Os resultados apresentados indicam uma maior participação dos homens no uso de métodos anticoncepcionais, 
Tabela 2

Variáveis associadas ao uso de algum método contraceptivo e ao uso de métodos com participação masculina.

\begin{tabular}{|c|c|c|c|c|}
\hline \multirow[t]{2}{*}{ Variáveis } & \multicolumn{2}{|c|}{$\begin{array}{l}\text { Algum método } \\
\qquad(n=360)\end{array}$} & \multicolumn{2}{|c|}{$\begin{array}{c}\text { Método com } \\
\text { participação masculina } \\
(n=283)^{\star \star}\end{array}$} \\
\hline & $\%$ & $\mathrm{p}$ & $\%$ & $\mathrm{p}$ \\
\hline \multicolumn{5}{|l|}{ Cuidado c/ filhos* } \\
\hline participavam ativamente & 88,4 & 0,084 & 39,3 & 0,437 \\
\hline pouco participavam & 78,1 & & 33,9 & \\
\hline \multicolumn{5}{|l|}{ Renda } \\
\hline 이-10 salários & 72,4 & 0,078 & 21,4 & $<0,001$ \\
\hline 10|-20 salários & 85,4 & & 31,6 & \\
\hline 20 ou mais salários & 79,2 & & 52,5 & \\
\hline \multicolumn{5}{|l|}{ Idade } \\
\hline menos de 40 anos & 83,1 & 0,061 & 37,8 & 0,915 \\
\hline 40 anos ou mais & 74,5 & & 37,9 & \\
\hline \multicolumn{5}{|l|}{ Escolaridade } \\
\hline até 8 série & 73,4 & 0,206 & 19,8 & $<0,001$ \\
\hline ensino médio & 83,0 & & 30,8 & \\
\hline $\begin{array}{l}\text { superior completo/ } \\
\text { incompleto }\end{array}$ & 81,0 & & 50,3 & \\
\hline \multicolumn{5}{|l|}{ Filhos } \\
\hline nenhum & 67,3 & 0,09 & 57,6 & $<0,001$ \\
\hline $1-2$ & 81,6 & & 42,5 & \\
\hline 3 ou mais & 78,3 & & 22,2 & \\
\hline \multicolumn{5}{|l|}{ Escolaridade parceira } \\
\hline até 8ạ série & 74,8 & 0,333 & 21,4 & $<0,001$ \\
\hline ensino médio & 78,7 & 42,6 & & \\
\hline $\begin{array}{l}\text { superior completo/ } \\
\text { incompleto }\end{array}$ & 81,9 & 48,9 & & \\
\hline \multicolumn{5}{|l|}{ Cor } \\
\hline branca & 79,8 & 0,350 & 41,8 & 0,013 \\
\hline não branca & 74,0 & 22,8 & & \\
\hline \multicolumn{5}{|l|}{ Grupo } \\
\hline docente/aluno & 79,7 & 0,801 & 54,7 & $<0,001$ \\
\hline funcionário/trabalhador & 78,0 & 27,7 & & \\
\hline \multicolumn{5}{|c|}{ Escolha método contraceptivo } \\
\hline homem & & & 100,0 & $<0,001$ \\
\hline casal & 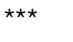 & & 55,6 & \\
\hline parceira/médico & & & 9,5 & \\
\hline Total & 78,6 & & 37,8 & \\
\hline
\end{tabular}

* Excluídos 49 homens que referiram não ter filhos vivos.

** Excluídos 77 homens que não usavam métodos contraceptivos por ocasião da entrevista.

*** Variável analisada somente para o uso de métodos com participação masculina. confirmando uma tendência que vem sendo apontada nesta última década no Brasil. Os dados nacionais da PNDS de 1996 apontam uma proporção três vezes maior de usuários de vasectomia e duas vezes maior de usuários de preservativo, em comparação com a pesquisa de 1986, na qual o uso referido da vasectomia foi de $0,8 \%$ entre as mulheres unidas, e o preservativo foi apontado como método em uso por 1,7\% delas (BEMFAM/IRD, 1987). Em 1996, o uso da vasectomia subiu para $2,6 \%$ e o preservativo passou a responder por 4,4\% (BEMFAM/Macro International, 1997). Para o Estado de São Paulo, as proporções de uso desses métodos praticamente dobraram nesse período de dez anos: o uso de preservativo foi referido por $3,1 \%$ das mulheres unidas em 1986 e por $6,9 \%$ delas em 1996; a vasectomia passou de $2,4 \%$ a $6,1 \%$ nesse período (BEMFAM/IRD, 1987; BEMFAM/Macro International, 1997).

Além de confirmar essa tendência, o uso de preservativo e de vasectomia pelos homens deste estudo $-18 \%$ e $12 \%$ respectivamente - ultrapassou em muito a prevalência detectada na última PNDS. Isso se deve, em parte, ao fato de que a amostra em questão apresenta um elevado perfil de escolaridade, que não corresponde ao da população em geral. Porém, essa limitação, na verdade, acaba por ser um elemento explicativo do que se observou, na medida em que, ao analisarem-se os dados da PNDS de 1996, verificou-se que a participação masculina no uso de métodos contraceptivos foi tanto maior, quanto mais elevado o nível de escolaridade dos entrevistados (Badiani \& Camarano, 1998). Os resultados da PNDS apontaram que a prevalência de preservativo era de $6,7 \%$ entre os homens unidos que tinham até quatro anos de escolaridade, em comparação com 14,3\% entre os que tinham escolaridade maior de 12 anos; a vasectomia foi referida por $1,3 \%$ dos homens do primeiro grupo e por $8 \%$ daqueles com maior escolaridade (BEMFAM/Macro International, 1997).

Da mesma forma, no presente estudo também se observou que a maior escolaridade da parceira estava relacionada ao uso tanto de algum método de participação masculina, quanto da vasectomia e do preservativo especificamente. A mesma tendência pode ser verificada na PNDS de 1996, em que foi maior a referência ao uso desses métodos entre as mulheres unidas que tinham 12 ou mais anos de escolaridade (BEMFAM/Macro International, 1997). Isto remete à discussão de que o maior grau de instrução da mulher é relevante para o estabelecimento de um melhor equilíbrio nas decisões contraceptivas. Esse estudo mostra que a escolaridade do homem é importante e que a gran- 
de semelhança na escolaridade do casal impossibilita distinguir qual delas é de maior relevância. A demografia já tem apontado que a escolaridade elevada da mulher produz um resultado efetivo na regulação da fecundidade porque se relaciona ao maior conhecimento real acerca dos métodos anticoncepcionais e à sua correta utilização, bem como à redução no número de filhos desejado e alcançado (Mahmud \& Johnston, 1994; Mahmood \& Ringheim, 1997; Martine, 1996). Além disso, o acesso à educação é um dos fatores que interfere positivamente no equilíbrio das relações de gênero, dando mais voz à mulher e criando maior receptividade por parte do homem na discussão sobre o assunto (Badiani \& Camarano, 1998; Lasee \& Becker, 1997).

Há de ressalvar-se, também, que a maioria dos participantes da pesquisa, por estarem inseridos na comunidade universitária, tinha, em relação ao restante da população, oportunidades diferenciadas quanto ao acesso a informações sobre anticoncepção e à possibilidade de discutirem e ouvirem opiniões diferentes sobre diversos assuntos, inclusive sobre saúde reprodutiva e relações de gênero. Outro aspecto relevante, possivelmente relacionado com os resultados aqui exibidos, é o de que, no Estado de São Paulo, as prevalências de uso de preservativo $(6,9 \%)$ e de vasectomia $(6,1 \%)$ são as maiores do Brasil (BEMFAM/Macro International, 1997). Na cidade de Campinas, onde se realizou a pesquisa, essas prevalências são tidas como ainda maiores - acima de 10\% (Cecatti \& Faúndes, 1995; Osis \& Faúndes, 1997), indicando, entre outras coisas, que o acesso a tais métodos é mais fácil. A própria Universidade em que se realizou o estudo possui um Ambulatório de Planejamento Familiar que oferece diariamente ações educativas e contempla a distribuição do preservativo, quando solicitado. $\mathrm{Na}$ época da pesquisa, esse ambulatório também era porta de acesso à vasectomia realizada no Hospital de Clínicas da Universidade (Marchi, 2001).

Essas peculiaridades da amostra estudada, discutidas até aqui, também são elementos importantes para explicar por que o perfil da prevalência de métodos foi distinto daquele que se tem construído por meio de pesquisas de base populacional. Embora a laqueadura ainda tenha sido o método mais referido pelos entrevistados (cerca de $27 \%$, no geral), sua prevalência foi bem menor, se comparada aos $40 \%$ observados na última PNDS (BEMFAM/Macro International, 1997). A pílula, porém, perdeu sua costumeira segunda posição entre os métodos mais usados, sendo ultrapassada pelo preservativo. Essa situação relaciona-se a que quase a metade da amostra estudada tinha menos de qua-

\begin{tabular}{|c|c|c|c|}
\hline $\begin{array}{l}\text { Variáveis associadas ao uso de al } \\
\text { e ao uso de método com particip }\end{array}$ & $\begin{array}{l}\text { método contra } \\
\text { masculina. }\end{array}$ & eptivo & \\
\hline Variáveis & Coeficiente & E.P. coeficiente & $\mathbf{p}$ \\
\hline \multicolumn{4}{|l|}{ Uso de algum método $(n=301)$} \\
\hline Idade (Anos) & $-0,068$ & 0,016 & $<0,001$ \\
\hline Constante & 4,409 & 0,745 & $<0,001$ \\
\hline \multicolumn{4}{|c|}{$\begin{array}{l}\text { Uso de método com participação } \\
\text { masculina }(n=241)\end{array}$} \\
\hline Número de filhos vivos (> 2) & $-1,179$ & 0,256 & $<0,001$ \\
\hline
\end{tabular}

renta anos de idade, o que, ao lado da maior escolaridade (pouco mais da metade tinha o nível superior), favorece o uso do preservativo e tende a diminuir a prevalência de esterilização feminina, aumentando a participação masculina na contracepção (Badiani \& Camarano, 1998). De fato, nesta amostra, embora a prevalência de esterilização seja de cerca de $40 \%$, ela se divide entre laqueadura (27\%) e vasectomia (12\%) de forma distinta do que ocorre na população em geral, indicando que, entre os entrevistados deste estudo, os homens dispuseram-se a assumir mais a responsabilidade da opção por um método definitivo.

Outro ponto a ser salientado é o de que o uso de algum método de participação masculina, e especificamente o do preservativo, esteve associado ao menor número de filhos. Este resultado condiz com a situação de que, à exceção da vasectomia, todos os métodos de participação masculina têm uma taxa de falha mais alta que a dos demais métodos femininos, e os casais com maior número de filhos procuram métodos de maior eficácia, que são alguns dos femininos (Ringheim, 1996).

Chama a atenção, no entanto, o fato de que o uso da vasectomia não esteve associado ao maior número de filhos, como ocorre comumente com a laqueadura (Osis, 1998; Vieira, 1998). Por outro lado, a vasectomia associou-se a ter sido o homem a pessoa que escolheu o método em uso pelo casal. Isto pode indicar que a maior divisão de responsabilidades na anticoncepção contribui para que haja uma perspectiva diferente acerca do planejamento familiar, como ação preventiva, e não como último recurso. Vale lembrar que esse enfoque foi preconizado, na Conferência do Cairo, como objetivo primário dos programas de planejamento familiar, que é o de ajudar os indivíduos a alcançarem os seus alvos reprodutivos de maneira sau- 
Tabela 4

Variáveis associadas ao uso de preservativo e vasectomia entre usuários de métodos contraceptivos.

\begin{tabular}{|c|c|c|c|c|}
\hline \multirow[t]{2}{*}{ Variáveis } & \multicolumn{2}{|c|}{ Preservativo $(n=283)$} & \multicolumn{2}{|c|}{ Vasectomia $(n=283)$} \\
\hline & $\%$ & $p$ & $\%$ & $p$ \\
\hline \multicolumn{5}{|l|}{$\begin{array}{l}\text { Escolha do método } \\
\text { contaceptivo }\end{array}$} \\
\hline homem & 35,0 & $<0,001$ & 60,0 & $<0,001$ \\
\hline casal & 28,1 & & 14,1 & \\
\hline parceira/médico & 5,6 & & 2,4 & \\
\hline \multicolumn{5}{|l|}{ Escolaridade parceira } \\
\hline até $8 \underline{a}$ série & 12,6 & 0,034 & 4,8 & 0,003 \\
\hline ensino médio & 16,7 & & 12,8 & \\
\hline superior & 23,7 & & 17,4 & \\
\hline \multicolumn{5}{|l|}{ Filhos } \\
\hline nenhum & 39,4 & $<0,001$ & 0 & 0,052 \\
\hline $1-2$ & 20,6 & & 15,0 & \\
\hline 3 ou mais & 6,7 & & 11,2 & \\
\hline \multicolumn{5}{|l|}{ Cuidado com os filhos } \\
\hline participavam ativamente & 18,0 & 0,548 & 13,1 & 0,899 \\
\hline pouco participavam & 14,8 & & 13,8 & \\
\hline \multicolumn{5}{|l|}{ Grupo } \\
\hline docente/aluno & 28,3 & 0,001 & 16,0 & 0,155 \\
\hline funcionário/trabalhador & 12,4 & & 9,6 & \\
\hline \multicolumn{5}{|l|}{ Escolaridade } \\
\hline até 8 a série & 9,9 & 0,004 & 5,5 & 0,060 \\
\hline ensino médio & 12,8 & & 12,8 & \\
\hline superior & 24,8 & & 15,7 & \\
\hline \multicolumn{5}{|l|}{ Renda } \\
\hline 이-10 salários & 13,3 & 0,073 & 3,6 & $<0,001$ \\
\hline 10|-20 salários & 15,8 & & 6,6 & \\
\hline 20 ou mais salários & 22,9 & & 21,2 & \\
\hline \multicolumn{5}{|l|}{ Cor } \\
\hline branca & 21,3 & 0,013 & 12,0 & 0,865 \\
\hline não branca & 7,0 & & 12,3 & \\
\hline \multicolumn{5}{|l|}{ Idade } \\
\hline menos de 40 anos & 20,3 & 0,404 & 10,5 & 0,430 \\
\hline 40 anos ou mais & 16,4 & & 14,3 & \\
\hline Total* & 18,4 & & 12,0 & \\
\hline
\end{tabular}

*Excluídos 77 homens que não usavam métodos contraceptivos por ocasião da entrevista. dável, e não o de limitar tais alvos (Jain \& Bruce, 1994).

Entretanto, é preciso ressaltar aqui que essa escolha do homem de fazer a vasectomia pode ser vista, na verdade, como sua participação em encerrar a fecundidade e não em regulá-la de fato. Isso ocorre porque, por um lado, há poucas alternativas contraceptivas que possam ser de iniciativa e realização apenas do homem e, por outro, porque os homens tenderiam a intervir nas decisões contraceptivas apenas no momento em que consideram que as mulheres já não podem resolver a situação sozinhas e eles devem arcar com sua responsabilidade de chefes de família (Marchi, 2001). Nesse sentido, Arilha (1999) argumenta, com base em resultados de pesquisa, que tanto os homens, como as mulheres, na verdade, consideram que a liderança dos processos reprodutivos é das mulheres, ao mesmo tempo em que é dos homens a responsabilidade de sustentar a família. Sendo assim, sentem-se compelidos a intervir efetivamente nas decisões reprodutivas quando acreditam que chegaram aos limites de sua capacidade de provedores. Essa autora salienta que os homens percebem o seu papel reprodutivo como sendo social e não corporal, razão pela qual agem nessa esfera motivados por seu senso de dever para com a família.

Essa mesma perspectiva se acha presente nas considerações de Ramírez-Gálvez (1999), de que a participação masculina nas práticas contraceptivas também é mediada pelo tipo de relação em que ocorrem. Embora a responsabilidade por essas práticas ainda seja atribuída às mulheres, os homens tendem a assumi-la como sua tanto mais quanto a relação com a mulher seja estável. Conseqüentemente, espera-se que, no contexto de uma relação conjugal-familiar, eles se sintam no dever social de participar.

Finalmente, o uso da vasectomia também se associou à maior renda familiar (superior a vinte salários mínimos), o que configura um quadro de bastante coerência dos achados deste estudo. Esse nível de renda deve-se, em parte, provavelmente ao elevado grau de escolaridade dos participantes e suas parceiras, mas também atua como um diferencial em relação ao uso de métodos anticoncepcionais e ao planejamento familiar, conforme já observado por outros autores (Alves, 1996; Camarano \& Beltrão, 1995; Morell \& Campanário, 1996). Além disso, à época da pesquisa, ainda não estava em vigor a Lei sobre Planejamento Familiar (Brasil, 1997), de maneira que o acesso à vasectomia dependia, em parte, de ter-se condições de pagá-la.

Portanto, os resultados aqui discutidos, embora não generalizáveis para a população geral, 
mostraram coerência com outros estudos do mesmo tipo e indicam que existe uma possibilidade de se concretizarem, na sociedade brasileira, a médio e longo prazo, mudanças importantes na perspectiva masculina quanto à contracepção. Em relação a isto, tais resultados são extremamente encorajadores, já que se sabe que muitas mudanças culturais iniciam-se entre os indivíduos com maior nível de instrução (Heilborn, 1992) e que a identidade de gênero não é estática, mas intensamente mutante (Bandeira, 1999).

Ao mesmo tempo, evidencia-se a necessidade de investir-se na educação de homens e mulheres, uma vez que esta, neste estudo, tanto quanto em outros já citados anteriormente, parece apresentar-se como um divisor de águas no equilíbrio das relações de gênero. Entendese que, além dos conteúdos formais que têm que ser comunicados, deve haver um esforço para incorporar-se a reflexão acerca da dinâmica das relações e dos papéis sociais.

Porém, não se há de pensar que isso seja uma tarefa fácil. É complexa e exige, mesmo, vontade política de interferir positivamente na educação, criando ambiente favorável à abordagem das questões de gênero, o que permitiria, desde cedo, discussão e reflexão acerca dos papéis e das responsabilidades de homens e mulheres na sociedade.

Outro ponto a ser considerado é o acesso a serviços de saúde reprodutiva de boa qualidade. Para a grande maioria da população tais serviços não estão disponíveis. Estudos qualitativos indicam que existe falta de ações educativas, insumos, incluindo métodos anticoncepcionais, falta de seguimento adequado, de aten-

\section{Agradecimentos}

À Fundação Ford pelo apoio financeiro para realização da pesquisa original e à Organização Mundial de Saúde e ao Conselho Nacional de Desenvolvimento Científico e Tecnológico pela concessão de bolsa de estudo durante o mestrado. Um reconhecimento especial a toda equipe do Centro de Pesquisas Materno-Infantis de Campinas pelo apoio e suporte durante o desenvolvimento da dissertação.

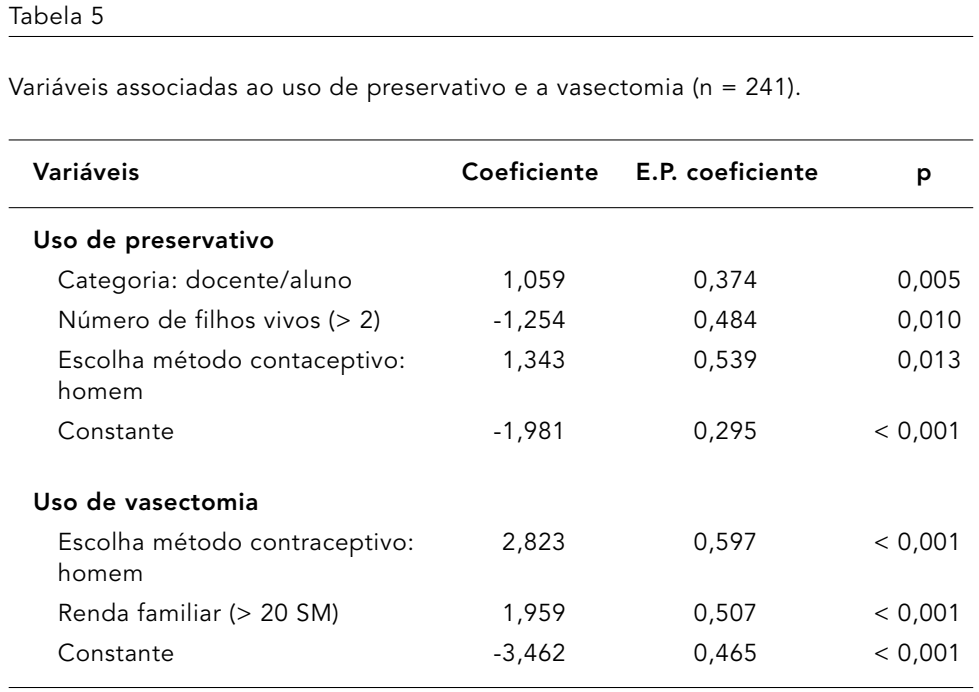

ção integral e humanizada, havendo também deficiência na competência técnica dos provedores (Díaz \& Díaz, 1999).

Finalmente, há que se considerar que essa tarefa de disponibilizar atendimento integral à saúde sexual e reprodutiva de homens e mulheres esbarra em um obstáculo interno a ser superado, qual seja o padrão das relações de gênero predominante na dinâmica de poder que permeia as relações nos serviços de saúde e na elaboração das políticas públicas. O modelo hegemônico de masculinidade parece prevalecer nesses ambientes, ainda quando as posições sejam ocupadas por mulheres. Portanto, a superação desse padrão exige, por certo, esforço não só dos homens, como das mulheres.

\section{Referências}

ALVES, J. E. D., 1996. Relações de gênero e transição da fecundidade. In: X Encontro Nacional de Estudos Populacionais, Anais, pp. 1455-1472, Caxambu: Associação Brasileira de Estudos Populacionais.

ANONYMOUS, 1992. Los hombres y la planificación familiar. Network, 7:4-35.

ANONYMOUS, 1998. Men and reproductive health. Network, 18:4-31.

ARMITAGE, P. \& BERRY, G., 1987. Statistical Methods in Medical Research. Oxford: Blackwell Scientific Publications.

ARILHA, M., 1999. Homens, saúde reprodutiva e gênero: O desafio da inclusão. In: Questões de Saúde Reprodutiva (K. Giffin \& S. Costa, org.), pp. 455-467, Rio de Janeiro: Editora Fiocruz. 
AZEREDO, S. \& STOLCKE, V., 1991 Direitos Reprodutivos. São Paulo: Fundação Carlos Chagas.

BADIANI, R. \& CAMARANO, A. A., 1998. Homens brasileiros: Percepções, conhecimentos e atitudes em saúde reprodutiva. In: XI Encontro Nacional de Estudos Populacionais, Anais, pp. 925-943, Caxambu: Associação Brasileira de Estudos Populacionais.

BANDEIRA, L., 1999. Relações de gênero, corpo e sexualidade. In: Saúde Sexual e Reprodutiva no Brasil (L. Galvão \& J. Díaz, org.), pp. 180-197, São Paulo: Editora Hucitec/Population Council.

BEMFAM (Sociedade Civil Bem-Estar Familiar no Brasil)/IRD (Instituto para Desenvolvimento de Recursos), 1987. Pesquisa Nacional sobre Saúde Materno-Infantil e Planejamento Familiar: Brasil, 1986. Rio de Janeiro: BEMFAM.

BEMFAM (Sociedade Civil Bem-Estar Familiar no Brasil) /DHS (Programa de Pesquisas de Demografia e Saúde Macro International Inc.), 1997. Pesquisa Nacional sobre Demografia e Saúde: Brasil, 1996. Rio de Janeiro: BEMFAM.

BRASIL, 1997. Lei Ordinária no 9263, de 12 de janeiro de 1996. Regula o parágrafo 7 do artigo 226 da Constituição federal, que trata do planejamento familiar, estabelece penalidades e dá outras providências. Partes vetadas correspondentes aos artigos 10, 11, 14 e 15. Brasília: Diário Oficial da União, col. 1, p. 17989, 20 ago.

CAMARANO, A. A. \& BELTRÃO, K. I., 1995. Dinâmica demográfica por nível de renda. Revista Brasileira de Estudos Populacionais, 12:81-112.

CECATTI, J. G. \& FAÚNDES, A., 1995. O Impacto das Altas Taxas de Cesárea sobre a Fecundidade de uma População. Um Estudo de Coorte Retrospectiva em Campinas, Brasil. Relatório de Pesquisa, Campinas: Centro de Pesquisas Materno-Infantis de Campinas.

DÍAZ, M. \& DÍAZ, J., 1999. Qualidade de atenção em saúde reprodutiva: Estratégias para mudanças. In: Saúde Sexual e Reprodutiva no Brasil (L. Galvão \& J. DÍAZ, org.) pp. 209-233, São Paulo: Editora Hucitec/Population Council.

DUARTE, G. A., 2000. Contracepção e Aborto: Perspectiva Masculina. Dissertação de Mestrado, São Paulo: Faculdade de Saúde Pública, Universidade de São Paulo.

HEILBORN, M. L., 1992. Vida a dois: Conjugalidade igualitária e identidade sexual. In: VIII Encontro Nacional de Estudos Populacionais. Anais, pp. 2529, Brasília: Associação Brasileira de Estudos Populacionais.

HOSMER, D. W. \& LEMESHOW, S., 1989. Applied Logistic Regression. New York: John Wiley and Sons.

HULTON, L. \& FALKINGHAM, J., 1996. Male contraceptive knowledge and practice: What do we know? Reproductive Health Matters, 7:90-100.

JAIN, A. \& BRUCE, J., 1994. A reproductive health approach to the objectives and assessment of family planning programs. In: Population Policies Reconsidered: Health, Empowerment, and Rights (G. Sem, A. Germain \& L. C. Chen, ed.), pp. 193-209, Boston: Harvard University Press.
LASEE, A. \& BECKER, S., 1997. Husband-wife communication about family planning contraceptive use in Kenya. International Family Planning Perspectives, 23:15-20.

MAHMOOD, N. \& RINGHEIM, K., 1997. Knowledge approval and communication about family planning as correlates of desired fertility among spouses in Pakistan. International Family Planning Perspectives, 23:122-129.

MAHMUD, S. \& JOHNSTON, A. M., 1994. Women's status, empowerment, and reproductive outcomes. In: Population Policies Reconsidered: Health, Empowerment, and Rights (G. Sem, A. Germain \& L. C. Chen, ed.), pp. 193-209, Boston: Harvard University Press.

MARCHI, N. M., 2001. Vasectomia: Razões da Opção de Casais pelo Método. Dissertação de Mestrado, São Paulo: Faculdade de Saúde Pública, Universidade de São Paulo.

MARTINE, G., 1996. Brazil's fertility decline, 19651995: A fresh look at key factors. Population and Development Review, 22:47-75.

MORELL, M. G. G. \& CAMPANÁRIO, P., 1996. Hipóteses da homogeneização da anticoncepção: Evidências para uma polêmica. In: X Encontro Nacional de Estudos Populacionais. Anais, pp. 1391-1413, Caxambu: Associação Brasileira de Estudos Populacionais.

MUNDIGO, A. I., 1995. Papéis Masculinos, Saúde Reprodutiva e Sexualidade, Conferência Internacional sobre População. São Paulo: Fundação MacArthur.

OSIS, M. J. D., 1998. Esterilização e gravidez na adolescência: Fatores inter-relacionados. In: Seminário Gravidez na Adolescência (E. M. Vieira, M. E. L. Fernandes, P. Bailey \& A. McKay, org.), pp. 67-73, São Paulo: Associação Saúde da Família.

OSIS, M. J. D. \& FAÚNDES, A., 1997. Brasil: Estudo Comparativo das Conseqüências da Laqueadura na Vida das Mulheres. Relatório de Pesquisa. Campinas: Centro de Pesquisas Materno-Infantis de Campinas.

RAMIREZ-GALVEZ, M. C., 1999. Os Impasses do Corpo: Ausências e Preeminências de Homens e Mulheres no Caso do Aborto Voluntário. Dissertação de Mestrado, Campinas: Instituto de Filosofia e Ciências Humanas, Universidade Estadual de Campinas.

RINGHEIM, K., 1996. Whither methods for men? Emerging gender issues in contraception. Reproductive Health Matters, 7:79-89.

VIEIRA, E. M., 1998. O arrependimento após esterilização feminina. Cadernos de Saúde Pública, 14: 59-68.

Recebido em 19 de abril de 2002

Aprovado em 14 de agosto de 2002 